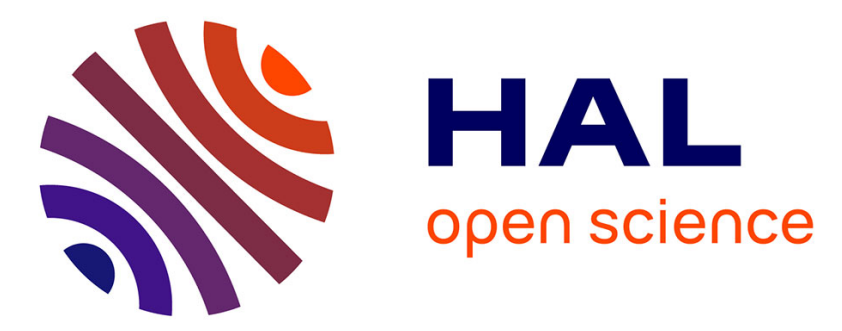

\title{
What Makes an Orienteer an Expert? A Case Study of a Highly Elite Orienteer's Concerns in the Course of Competition
}

\author{
Anne-Claire Macquet, David W Eccles, Etienne Barraux
}

\section{To cite this version:}

Anne-Claire Macquet, David W Eccles, Etienne Barraux. What Makes an Orienteer an Expert? A Case Study of a Highly Elite Orienteer's Concerns in the Course of Competition. Journal of Sports Sciences, 2012, 30 (1), pp.91-99. 10.1080/02640414.2011.617774 . hal-01727017

\section{HAL Id: hal-01727017 https://hal-insep.archives-ouvertes.fr/hal-01727017}

Submitted on 8 Mar 2018

HAL is a multi-disciplinary open access archive for the deposit and dissemination of scientific research documents, whether they are published or not. The documents may come from teaching and research institutions in France or abroad, or from public or private research centers.
L'archive ouverte pluridisciplinaire HAL, est destinée au dépôt et à la diffusion de documents scientifiques de niveau recherche, publiés ou non, émanant des établissements d'enseignement et de recherche français ou étrangers, des laboratoires publics ou privés. 
Full title: What Makes an Orienteer an Expert? A Case Study of a Highly Elite Orienteer’s Concerns in the Course of Competition

Anne-Claire Macquet ${ }^{1}$, David W. Eccles ${ }^{2}$, and Etienne Barraux ${ }^{3}$

${ }^{1}$ French Institute of Sports (INSEP), Paris, France; ${ }^{2}$ Florida State University, Tallahassee; ${ }^{3}$ East Paris-Creteil University, France

Correspondence concerning this article should be addressed to Anne-Claire Macquet, INSEP; Service Recherche; 11, avenue du Tremblay; 75012 Paris, France

e-mail : anne-claire.macquet@insep.fr

\section{Running title: ORIENTEER'S CONCERNS DURING COMPETITION}

Keywords: navigation, reflective practice, running pace, performance mediation processes, skilled performance.

Acknowledgments. This study was supported by a grant from the French Ministry of Health and Sports. The authors are grateful to the orienteer for his participation to this study and to André Hermet for his helpful comments during data processing. 


\begin{abstract}
This article reports on a highly elite orienteer's cognitive activity over the course of two international competitions. We characterise the orienteer's concerns in relation to the problems raised during the competitions. The participant wore a head-mounted video camera throughout performance to enable the capture of an events record from the participant's perspective. During a post-performance self-confrontation interview, the participant was played the video and asked to describe his activity in relation to the events observed. The interview data were then used to identify the orienteer's concerns at each point in time during the races. These "local" concerns were then compared and subsequently classified to characterise the typical concerns of the participant. Results showed three typical concerns: (a) find the controls faster than the opponents; (b) optimise running pace throughout the race; and (c) reflect on actions undertaken during performance. Results suggest the performer used a range of knowledge-driven strategies that enhanced the efficiency of task performance, and flexibly switched between strategies and decision-options in the face of presented changes in the task status. He also engaged in various reflective processes concurrent with performance that augmented the use of these strategies. In conclusion, this study provides insight into the cognitive processes underlying expert performance in sports characterised by decisionmaking under complexity, uncertainty, and time pressure.
\end{abstract}




\section{Introduction}

A key determinant of experts' superiority is their extensive period of preparation in the domain, which typically involves over a decade of full-time engagement in deliberate practice (Ericsson, Krampe, \& Tesch-Römer, 1993; Ericsson, 2003; Williams \& Hodges, 2004). This preparation allows them to develop cognitive skills and strategies that enhance the efficiency with which information from their domain is processed. It also leads to increases in the amount of domain-specific knowledge acquired and the adaptations to memory that allow for rapid and flexible encoding and retrieval of domain-specific information during performance (Ericsson \& Kintsch, 1995; McPherson, 1999). These adaptations support rapid and reliable performance mediation processes, including planning, monitoring, and evaluation, during performance. Experts' enhanced performance mediation processes govern when, where, and how best to apply the skills and strategies that afford efficient information processing during performance.

One area of research contributing to these findings has involved orienteering (e.g., Eccles, Walsh, \& Ingledew, 2002a), in which performers win by navigating through points (called controls) in wild terrain faster than their opponents. A control is a flag fixed in the ground, from which hangs a "punch", which is used to register that a control has been visited. The orienteer must navigate to each control in a specific order using a compass and map. The distance from one control to the next is known as a "leg". The map is provided at the start of the race and displays terrain information such as contours and vegetation, and the location of the controls. Eccles et al. (2002a) developed a theory of cognition in orienteering and showed that successful performance requires attention to three sources of information: the map (to know the control locations and where one is located in the terrain); the surrounding environment (to compare it with its mapped representation); and travel (watching where one is going while running to avoid hazards). Owing to finite attentional resources, the orienteer cannot attend simultaneously to all three sources of information and thus must switch attention between the sources leading to trade-offs in attention between them. For example, trading off too much attention from travel to attend to the map can leads to collisions with hazards or slips. 
However, more skilled orienteers develop strategies to circumvent these attentional limitations. They use cognitive strategies such as simplifying the information provided on the map to the minimum required to navigate (Seiler, 1990; Eccles et al., 2002a, b). Specifically, skilled performers reduce the map information required to navigate by selecting features from the map that are easy to locate visually in the terrain such as large boulders. They also strategically schedule their attention by using "quiet periods" of navigation to attend to the map to plan ahead (Eccles et al., 2006). Skilled orienteers also use physical strategies to circumvent attentional limitations. For example, they fold and re-fold the map during competition so that only their present location is displayed, which reduces the visual search within the map required to find this location (Eccles, 2006, 2008).

Other studies involving locomotion over natural terrain under time constraints, such as fellrunning, have highlighted the factors affecting route choice through the terrain (e.g., Hayes \& Norman, 1984, 1994; Norman 2004; Scarf, 2007). For example, fell-runners use rules adapted from Naismith's rule developed for hikers to compare different routes and travel times over undulating terrain. Naismith's rule is to allow 20 min for every $1.6 \mathrm{~km}$ (1 mile) of travel plus $10 \mathrm{~min}$ for every $304 \mathrm{~m}$ (1000 feet) of ascent. Fell-runners also chose routes according to navigational simplicity and runability, defined as the ease with which one can run over an area of terrain given its roughness underfoot and the thickness of the surrounding vegetation.

These studies have provided insights into how skills are acquired in orienteering and other similar sports. However, a shortcoming of this research, and research on expertise in sports generally, is that few researchers have involved investigations of the cognitive activity of expert athletes in relation to specific competitive events. Performers are more likely to provide valid information about their use of cognitive strategies during performance if they are asked to recall thoughts experienced in relation to specific, real performances rather than to report about the cognitive strategies they use in their sport in general (Eccles, 2011). For example, while Eccles et 
al. (2002a) interviewed elite orienteers about their use of cognitive strategies, these authors only occasionally directed participants to provide information in relation to specific events.

A second limitation of the extant research is that few studies have involved attempts to understand performers' concerns in relation to entire competitive events. Little is known about how elite performers spend their time thinking during such events. For example, while Eccles et al. (2002a) identified cognitive strategies used by elite orienteers, they were not able to provide information about the extent to which these strategies are used within a given performance. Such information would be useful in understanding what makes individuals expert in sports with a strong cognitive (decision-making) component as well as other domains characterised by decision-making under complexity, uncertainty, and time pressure. It would also allow insights into how to develop to the expert level in these domains. Consequently, this study aims to identify, via post-performance interviews, the concerns of a highly elite orienteer throughout two specific competitive events.

On the basis of the extant theory and research on expert performance in general (e.g., Ericsson \& Kintsch, 1995), it was predicted that the orienteer's reports would indicate the use of a range of knowledge-driven skills and strategies that function to enhance task efficiency and in turn circumvent natural system limitations. On the basis of the extant theory and research concerning expert orienteering performance specifically (Eccles et al., 2002a), it was predicted that these skills and strategies would function to enhance orienteering efficiency at two levels: cognitively and physically. At the cognitive level, it was hypothesised that the cognitive strategy of navigational simplification as well as the physical strategy of folding the map would be used to reduce the attentional demands of navigating over a given distance. At the physical level, it was hypothesised that the orienteer would attempt to use the shortest and most energy-efficient running routes. An additional component of the study was, however, exploratory in nature. As described, unknown at this time is the extent to which these skills and strategies are used across the duration of competitive performances. The objective here was to identify whether, and how often the orienteer used these skills and strategies during performance. 
The method employed, and participant featuring in the study, were selected in an attempt to meet this objective. The method involved the participant wearing a head-mounted video camera throughout competitive performances to enable the capture of an events record from the participant's perspective. Following the performances, a self-confrontation interview was undertaken in which the participant was played the video and asked to describe his activity in relation to the events observed. The interview data were then used to identify the orienteer's concerns at each point in time during the performances. The study participant represented "a paradigm case”; his highly elite status gave him prototypical value (see Flyvbjerg, 2006). To elaborate, he had participated in the world orienteering championships for 13 consecutive years, winning gold at the sprint or middle distance six times. Since the present study, he competed at another world championship event, winning gold at the middle distance. Based on this record, it is arguable that he is currently the world's best orienteer, and also one of the best ever. Thus, to paraphrase Sears (1992, p. 148), the attempt here was to "know one performer well”. In doing so, we hoped to produce within the study of expert sports performance a detailed case study of an exemplar; a product deemed critical to the effectiveness of a scientific discipline (Flyvbjerg, 2006; see also Wolcott, 1995).

\section{Method}

\section{Participant}

A male orienteer, aged 29 years, volunteered to participate. As described above, he competed at a highly elite level. The study was approved by a local ethics committee.

\section{Data Collection}

The participant's cognitive activity was studied in relation to two international competitions. Competitions were middle distance races involving a total of 41 legs (15 for race 1 and 26 for race

2). Two types of qualitative data were collected at different times. The participant wore a head- 
mounted video camera throughout each competition to capture a video record of the events constituting the competition from the participant's perspective (Omodei, Wearing, \& McLennan, 1997; Omodei, McLennan, \& Withford, 1998; Eccles et al., 2006). The videotape was used to provide behavioural and contextual data but also to stimulate the orienteer to re-experience the race during the interview. A self-confrontation interview was then conducted with the participant in relation to each competition. Interviews were conducted within five hours of the competition by a researcher with previous experience of undertaking self-confrontation interviews with athletes. The first interview lasted 75 minutes and the second 120 minutes. For each interview, the video recording of the competition was played and the participant was invited to describe and comment upon his activity during the course of action (i.e., to describe what he was doing, thinking, feeling, and perceiving). Interviews were recorded and transcribed verbatim.

\section{Data Processing}

Data were processed by two researchers using an inductive analysis (Corbin \& Strauss, 1990). Each researcher first divided the transcripts into meaningful units according to the orienteer's concerns. The concerns were then classified into categories according to their common features (see Table 1). Each category was labelled and its properties defined. As the data analysis proceeded, another level of interpretation emerged from a comparison between properties of categories. Data were constantly compared until saturation was reached, which occurred when no more new categories emerged from the data. The two researchers then compared their results in terms of meaningful units and categories, and discussed any initial disagreement until social consensus was reached. Interview transcripts were divided into 207 meaningful units in race 1 and 552 in race 2. Units pertained to four first-order categories of concerns (called sub-categories). These categories were further classified into three second-order categories (called typical concerns). 


\section{Results}

Results are presented in three parts according to the typical concerns identified: (a) find the controls faster than the opponents; (b) optimise running pace throughout the race; and (c) reflect on actions undertaken during performance (see Table 2). The orienteer's cognitive activity during the races could be seen as an alternation between these concerns.

**** Table 2 near here****

\section{Find the Controls Faster than the Opponents}

The orienteer had to locate the controls on the map and find them in the terrain faster than his opponents. At the starting point of each race, he first located his current position on the map and then folded it and arranged it in his hand so that only the part of the map concerning the terrain over which he was currently required to navigate was displayed. This type of concern represented $67 \%$ of all of the concerns mentioned (see Table 2) and was mentioned throughout each race. It comprised two sub-categories: simplify the map to navigate and use the shortest and most energyefficient running routes.

Simplify the map to navigate. The large amount of information contained on the map and continual shaking of the map arising during running creates an imperative to reduce needing to obtain information from the map, as it necessarily makes the orienteer slow down. Consequently, the orienteer attempted to "simplify" the information obtained from the map to the minimum required to navigate accurately and rapidly. He would first obtain a general sense of a route by identifying obvious running routes from the current control to the next one. He then strived to find map features, that he termed "checkpoints", that he knew from experience would be easily recognisable in the terrain, such as big rocks. He effectively divided each leg into a series of checkpoints; this process was completed as he proceeded through the leg. The orienteer identified the first checkpoint located between his current location and the location of the upcoming control 
and just before arriving at this first checkpoint, located the next such point from the map, and so on until he approached the last point within the leg, which was located just before the control. This last point he called an attack point. For example, the orienteer said:

"When I look at the map, there's much information. Some elements stand out more than others. If we want to go fast, we've to rely on big recognisable features on the map that also stand up from the horizon. These features here are the rocks. I build a mental image of the terrain according to these rocks and then I've to build a leg in relation to these rocks” (race 1, leg 1).

The orienteer memorised these checkpoints and while running, compared this memorised information with the actual terrain to check if it was congruent. Any inaccuracy in navigation could be corrected with few ramifications when the orienteer was some distance from the control. However, more accurate navigation was required as he neared the control to locate the small control flag. Therefore, the orienteer reduced his use of the simplification strategy and instead included more map information in his mental representation of the area around the control. Before registering his visit to the control using the punch device, he used the compass to identify the direction of the next control given his approach to the current control. This type of concern represented $53 \%$ of all of the concerns mentioned (see Table 2) and was mentioned in relation to all of the 41 legs.

Use the shortest and most energy-efficient running routes. The orienteer attempted to choose routes by making trade-offs between four terrain-related factors, which were length, runability, the surrounding vegetation, and navigational simplicity (i.e., the presence of highly distinguishable and recognisable terrain features), and one organism-related factor, which was current level of fatigue. He compared routes on the map, and attempted to use the shortest and most energy-efficient running route, and navigationally simplest route, given his level of fatigue. He frequently chose one route (before embarking on it) with the intention of switching to another if the first route transpired to afford energy-inefficient running. On occasion, before choosing a route, he 
decided to approach the route area to obtain more information about the nature of the terrain there. For example, the orienteer said:

“There's a dense vegetation zone on the map. I don't know yet how difficult it will be to cross, we haven't experienced this type of vegetation before: it's half open and dense and low vegetation. I tell myself we're in winter, so it should be possible to go straight across it. I can't

really avoid it, instead of by using a longer path. Going straight across it is a little risky, but I haven't got any other options. I'll see what it's like when I get there; if needed, I'll change routes" (race 2 , leg 4 ).

This type of concern represented 15\% of all of the concerns mentioned (see Table 2) and was mentioned in relation to 28 of the 41 legs.

\section{Optimise Running Pace throughout the Race}

The orienteer monitored and adjusted his running pace during the race to optimise his average running speed throughout the race. Monitoring and adjustments were necessary owing to changes over the race in various constraints, including: (a) runability; (b) proximity to other opponents; (c) navigational difficulties; (e) the stage of the leg (e.g., when the orienteer was leaving the control); and (f) fatigue experienced. The orienteer adjusted his speed to these constraints by: (a) running faster while on paths, leaving a control, and overtaking an opponent; (b) attempting to maintain running speed despite fatigue, contours, slippery ground, vegetation, and navigation difficulties; and (c) slowing down to pay more attention to the map and terrain or to recover physically. For example, the orienteer said: “I don't feel terrible but it's the first time in the race I feel fatigued. I try to maintain my speed despite the terrain contours” (race 1, leg 12). This type of concern represented $14 \%$ of all of the concerns mentioned (see Table 2) and was mentioned in relation to 30 of the 41 legs.

\section{Reflect on Actions Undertaken during Performance}


The orienteer attempted to reflect during performance on what had been done, what was being done, and what had to be done. This type of concern represented $18 \%$ of all of the concerns mentioned (see Table 2) and was mentioned occasionally throughout both races. This concern involved two sub-categories: (a) attempting to judge navigation; (b) deciding whether to use information about opponents.

Judging navigation. While running, the orienteer attempted to stand back from, and reflect on his navigation. He assessed his efficiency and stayed concentrated to find the controls rapidly and run quickly. He reflected in particular during "quiet” phases of the race (e.g., when there were few immediate navigational concerns) or when he began to detect problems with his navigation. He attempted to: (a) consider the difficulties he could face finding an upcoming control; (b) judge the precision of his current navigation; (c) judge his lucidity and tried to monitor potential perturbations (e.g., fatigue); and (d) maintain concentration when navigation was proceeding satisfactorily or increase concentration when a navigational error was committed and when finding a control was difficult. For example, the orienteer said:

"I'm looking at control 5 on the map. I'm on alert, I'm saying to myself this zone can be difficult: the relief is a little marked, there's a lot of vegetation, maybe reduced visibility. It's difficult to find the correct position when once has left the path. It's a risky control. I need to look more at the map." (race 2, leg 5).

This type of concern represented $15 \%$ of all of the concerns mentioned (see Table 2) and was mentioned in relation to 27 of the 41 legs.

Deciding whether to use information about opponents. In orienteering, competitors start a race at different time intervals to minimise the chances of meeting one another while competing and thus using one another as a navigational aid (e.g., one orienteer may follow another). However, orienteers do sometimes observe one another while competing. Such observations introduce a dilemma about whether to use these observations to influence navigation given that one's opponent 
might actually be committing a navigational mistake. Within the present study, the orienteer occasionally observed opponents but chose to follow his own directions unless he observed an opponent making a sudden direction change; a good indicator that the opponent had found the control. For example, the orienteer said:

"I see someone going out the bumps. I'm in the control axis. I try not to use information about opponents' movements because it can be risky. Here, it's additional information and I say to myself the control should be over there and I haven't seen it” (race 2, leg 5).

This type of concern represented 3\% of all of the concerns mentioned (see Table 2) and was mentioned in relation to 11 of 41 legs.

\section{Discussion}

These results are discussed in relation to two sets of findings related to expert performance. The first concerns experts' development of skills and strategies that enhance the efficiency of task performance. The second concerns experts’ development of enhanced online performance mediation processes.

\section{Evidence of Strategies Enhancing the Efficiency of Task Performance}

On the basis of the theory and research on expert performance (e.g., Ericsson \& Kintsch, 1995), it was predicted that the orienteer's reports would indicate the use of a range of knowledgedriven strategies that function to enhance task efficiency. On the basis of previous work on expert orienteering (Eccles et al., 2002a), it was predicted that these skills and strategies would function to increase navigational efficiency by simplifying the information required to navigate. Our results are in line with this prediction. The orienteer folded the map to help him visually locate his current map location. He also reduced the map information required to navigate by selecting for use map features he knew from experience would be easily recognisable and thus easy to locate visually in the terrain (i.e., checkpoints). This strategy was used to maximise the efficiency of the task and was 
abandoned only if the orienteer began to detect the onset of a navigational error. If this happened, he favoured a safer but less efficient strategy involving the identification of more, and "finer", terrain features to find out exactly where he was.

It was also hypothesised on the basis of prior research on expert orienteering performance (Eccles et al., 2002a) that the participant would provide reports indicating the use of knowledgedriven strategies that function to reduce the energy required to travel over a given distance in the terrain. Specifically, it was predicted that the orienteer would attempt to select from the map and then navigate the shortest and most energy-efficient running routes. The results here support this hypothesis. The participant investigated possible routes from the map and made trade-offs between terrain-related factors (length, runability, surrounding vegetation, and navigational simplicity) and organism-related factors (fatigue). These results are inconsistent with previous research on the use of rules adapted from Naismith’s rule (e.g., Hayes \& Norman, 1984). The orienteer did not really estimate travel times and distances for routes involving climb. He solely compared routes to make trade-offs. Future research should aim to explore in more detail how the orienteers choose their routes. On occasion, the orienteer decided to near the route to see whether it was relatively energyefficient in terms of running and/or simple in terms of navigation with a view to switching to an alternative route option if it was not. In other words, he anticipated the need to make, and actually made adjustments to his navigational strategy, consistent with the previous findings concerning expertise (e.g., McPherson \& Kernodle, 2003; Macquet \& Fleurance, 2007; Macquet, 2009).

These findings have implications for planning in other sports involving dynamic task environments (e.g., American football; see Eccles \& Tenenbaum, 2004) as well as for other nonsporting domains of a similar nature such as command and control in emergency responding and military operations (see Riley, Endsley, Bolstad, \& Cuevas, 2006). As in orienteering, there is likely a critical role in these domains for pre-identified back up plans, being prepared to change a plan if it proves ineffective in execution or a more effective plan becomes obvious, and engaging in anticipatory thought to identify when and how a current plan might need to be changed. 


\section{Evidence of Online Performance Mediation Processes}

This study also showed that beyond focusing on what he was currently doing, the orienteer reflected on actions undertaken during performance. This process of reflection involved the use of experience to interpret current performance and the difficulties faced or that could be faced and to consider how to maintain or improve current performance. For example, this process allowed the orienteer to: (a) understand a navigational error committed; (b) stop thinking about the error; and (c) adjust his level of attention to the map to avoid committing a similar error during the remainder of the race. It also allowed the orienteer to assess his understanding of current problems and possible solutions available to him, and to adjust performance to changes in conditions, such as a navigational error.

These results are consistent with existing theory about experts’ development of sophisticated online performance monitoring and evaluation processes (Ericsson \& Kintsch, 1995; McPherson, 1999). McPherson (1999) proposed the concept of a current event profile, an adaptation to longterm memory following extensive practice and experience in a specific sport domain. One function of the profile is to facilitate "higher order" performance mediation processes, including planning, monitoring, and evaluation of ongoing performance (McPherson \& Kernodle, 2003). These processes appear consistent with the processes of reflection documented in the current study. Few researchers have provided evidence of expert athletes’ engagement in such higher order processes (e.g., McPherson \& Kernodle, 2003; Baker, Côté, \& Deakin, 2005). Moreover, there have been few attempts to gain insight into a performer's concerns throughout an entire event so that the extent to which a specific strategy or set of strategies might be identified. The present study, however, showed that $15 \%$ of the performer's concerns were related to these higher order processes.

McPherson and Kernodle (2003) also proposed that current event profiles “may be used to compensate actions and make adjustments during time-constrained moments” (p. 144). This is consistent with the finding from the present study that the performer's evaluations of his current 
navigational performance lead to adjustments to his navigational strategy. Of particular note is the evidence of performance monitoring prior to any error being committed; that is, the orienteer monitored ongoing navigational performance proactively, even when he felt satisfied with his current level of navigation. Such monitoring presumably increases his sensitivity to the onset of the commission of an error so that errors can be avoided or corrected as soon as possible.

At the applied level, it is unknown whether the performance mediation processes identified here can be independently trained. Current theory asserts that these processes are afforded as a consequence of adaptations to long-term memory. These adaptations make possible the use of longterm memory during ongoing performance, so that long-term memory acts as an extension to working memory; an extension not afforded (or at least afforded less) to the less skilled performer, whose performance is limited by the natural limits of working memory (Ericsson \& Kintsch, 1995). Traditional conceptions of these adaptations propose that they are developed following extensive practice and experience in a domain. However, it is unknown whether they can only be developed following this extensive period of development or whether they can be specifically trained. While there have been recent efforts by sport psychologists to train performers to reflect on their performance retrospectively (e.g., Hanton, Cropley, \& Lee, 2009; Lee, Chesterfield, Shaw, \& Gayes, 2009), we know of no studies aimed at training performers to reflect concurrently during performance. This would seem a worthwhile avenue for future research.

Some limitations of this study must be noted. First, it did not feature non-experts for comparison. Thus, the extent to which non-expert orienteers engage in the activities described is unknown. However, previous studies of strategy use featuring only experts have contributed notably to the understanding of expert sports performance (e.g., Gould, Eklund, \& Jackson, 1993). Given the amount of data generated by qualitative studies of this type, researchers have often focused only on expert performers with the rationale that even if strategies reported by experts are used by nonexperts, the strategies are likely to be most sophisticated at the expert level. Second, the study featured only one participant and it could be argued that the results presented here are not 
representative of other skilled orienteers. However, studies of expert performance in mainstream (e.g., Ericsson, Delaney, Weaver, \& Mahadevan, 2004) and sport psychology (e.g., Nieuwenhuys, Hanin, \& Bakker, 2008) have often involved one or very few participants because, by definition, only a few individuals develop to the expert level. Lastly, in line with Sparkes’ (2009) observations, the sense of sight was effectively elevated over the other senses in the present study, as the participant was asked to comment about activity seen in a video film of his orienteering. Orienteers likely use their other senses to obtain information useful to performance. By way of evidence, the opening line of the text on orienteering by Boga (1997, p. v) refers to sensations of the natural environment (e.g., the sound of a "babbling brook”) as central to the orienteering experience. It would be of interest and use in future research to encourage orienteers to describe how a particular course was navigated with reference to all of the senses.

In conclusion, in the present study we investigated the cognitive activity of a highly elite performer over the entire course of competitive events. The performer was shown to utilise during performance a range of knowledge-driven strategies that enhanced the efficiency of task performance and to flexibly switch between strategies and decision-options in the face of presented changes in the task status. The performer was also shown to engage in a range of reflective processes concurrent with performance that augmented the use of these strategies. The continued study of the cognitive activity of expert athletes in domains such as orienteering will extend our understanding of skill acquisition and expert performance in sports with a strong cognitive component as well as in other domains characterised by decision-making under complexity, uncertainty, and time pressure. 


\section{References}

Baker, J., Côté, J., \& Deakin, J. (2005). Cognitive characteristics of expert, middle of the pack, and back of the pack ultra-endurance triathletes. Psychology of Sport and Exercise, 6, 551-558.

Boga, S. (1997). Orienteering. Mechanicsburg, PA: Stackpole Books.

Corbin, J., \& Strauss, A. (1990). Basics of qualitative research: Grounded theory. Procedures and techniques. Newbury Park, CA: Sage.

Eccles, D.W. (2006). Thinking outside the box: The role of environmental adaptation in the acquisition of skilled and expert performance. Journal of Sports Sciences, 24, 1103-1114.

Eccles, D.W. (2008). Experts' circumvention of processing limitations: An example from the sport of orienteering. Military Psychology, 20, 103-121.

Eccles, D.W. (2011). Verbal reports on cognitive processes. In G. Tenenbaum, R.C. Eklund, \& A. Kamata (Eds.), Handbook of measurement in sport and exercise psychology (pp. 103-117).

Champaign, IL: Human Kinetics.

Eccles, D. W., \& Tenenbaum, G. (2004). Why an expert team is more than a team of experts: A social-cognitive conceptualization of team coordination and communication in sport. Journal of Sport \& Exercise Psychology, 26, 542-560.

Eccles, D.W., Walsh, S.E., \& Ingledew, D.K. (2002a). A grounded theory of expert cognition in orienteering. Journal of Sport \& Exercise Psychology, 24, 68-88.

Eccles, D.W., Walsh, S.E., \& Ingledew, D.K. (2002b). The use of heuristics during route planning by expert and novice orienteers. Journal of Sports Sciences, 20, 327-337.

Eccles, D.W., Walsh, S.E., \& Ingledew, D.K. (2006). Visual attention in orienteers at different levels of experience. Journal of Sports Sciences, 24, 77-87. 
Ericsson, K.A. (2003). Development of elite performance and deliberate practice: An update from the expert performance approach. In J.L. Starkes, \& K.A. Ericsson (Eds.), Expert performance in sports (pp. 49-83). Champaign, IL: Human Kinetics.

Ericsson, K.A., Delaney, P., Weaver, G., \& Mahadevan, R. (2004). Uncovering the structure of a memorist’s superior “basic”' memory capacity. Cognitive Psychology, 49, 191-237.

Ericsson, K.A., \& Kintsch, W. (1995). Long term working memory. Psychological Review, 102, 211-245.

Ericsson, K.A., Krampe, R.T., \& Tesch-Römer, C. (1993). The role of deliberate practice in the acquisition of expert performance. Psychological Review, 100, 365-406.

Flyvberg, B. (2006). Five misunderstandings about case-study research. Qualitative Inquiry, 12, 219-245.

Gould, D., Eklund, R.C., \& Jackson, S.A. (1993). Coping strategies used by US Olympic wrestlers. Research Quarterly for Exercise and Sport, 64, 83-93.

Hanton, S., Cropley, B., \& Lee, S. (2009). Reflective practice, experience, and the interpretation of anxiety symptoms. Journal of Sports Sciences, 27, 517-533.

Hayes, M., \& Norman, J.M. (1984). Dynamic programming in orienteering: Route choice and the siting of controls. Journal of the Operational Research Society, 35, 791-796.

Hayes, M., \& Norman, J.M. (1994). Strategy in fell running: An analysis of the Bob Graham Round. Journal of the Operational Research Society, 45, 1123-1130.

Lee, S., Chesterfield, G., Shaw, D.J., \& Gayes, T. (2009). Editorial. Exploring the potential of reflective learning in sport. Reflective Practice, 10, 285-293.

Macquet, A.-C. (2009). Recognition within the decision-making process: A case study of expert volleyball players. Journal of Applied Sport Psychology, 21, 64-79. 
Macquet, A.-C., \& Fleurance, P. (2007). Naturalistic decision-making in expert badminton players. Ergonomics, 50, 1433-1450.

McPherson, S.L. (1999). Tactical differences in problem representations and solutions in collegiate varsity and beginner women tennis players. Research Quarterly for Exercise and Sport, 70, 369384.

McPherson, S.L., \& Kernodle, M.W. (2003). Tactics, the neglected attribute of expertise. In J. L. Starkes, \& K. A. Ericsson (Eds.) Expert performance in sports (pp. 137-168). Champaign, IL: Human Kinetics.

Norman, J.M. (2004). Running uphill: Energy needs and Naithsmith’s rule. Journal of the Operational Research Society, 55, 308-311.

Nieuwenhuys, A., Hanin, Y.L., \& Bakker, F.C. (2008). Performance-related experiences and coping during races: A case study of an elite sailor. Psychology of Sport and Exercise, 9, 61-76.

Omodei, M.M., McLennan, J., \& Withford, P. (1998). Using a head-mounted video camera and two stage replay to enhance orienteering performance. International Journal of Sport Psychology, 29, 115-131.

Omodei, M.M., Wearing, A., \& McLennan, J. (1997). Head-mounted video recording: A methodology for studying naturalistic decision making. In R. Flin, E. Salas, M. Strub, \& L. Martin (Eds.), Decision making under stress (pp. 137-146). Burlington, VT: Ashgate.

Riley, J. M., Endsley, M. R., Bolstad, C. A., \& Cuevas, H. M. (2006). Collaborative planning and situation awareness in Army command and control. Ergonomics, 49, 1139-1153.

Scarf, P. (2007). Route choice in mountain navigation, Naismith's rule, and the equivalence of distance and climb. Journal of Sports Sciences, 25, 719-726.

Sears, J. T. (1992). Researching the other/searching for self: Qualitative research on [homo]sexuality in education. Theory into Practice, 31, 147-156. 
Seiler, R. (1990). Decision making processing in orienteering: An action theoretical investigation. International Journal of Sport Psychology, 21, 36-45.

Sparkes, A. C. (2009). Ethnography and the senses: Challenges and possibilities. Qualitative Research in Sport and Exercise, 1, 21-35.

Williams, A.M., \& Hodges, N.J. (Eds.) (2004). Skill acquisition in sport: Research, theory, and practice. London, UK: Routledge.

Wolcott, H. F. (1995). The art of field work. Walnut Creek, CA: AltaMira Press. 
Table 1

\section{Examples of Meaningful Units, and First and Second Order Categories of Concerns}

\begin{tabular}{l} 
Meaningful units \\
\hline I'm registering my visit at the first control. I already know the \\
direction I must follow. I go to the re-entrant [a small valley] which is \\
here on the map. \\
I leave the control using the compass. I'm looking at the map to be \\
sure I've seen the most salient information; for example, the re- \\
entrant. \\
I'm saying to myself the direction is ok.
\end{tabular}

I'm trying hard to run uphill, so I'm looking at the map less often.

Here, I've got some problems with my shoes. I had some blisters, so I couldn't use my race shoes. I used my running shoes with a worn sole. So I must run carefully to avoid slipping.

I'm arriving at the top. I aim to using as much as possible the network of paths to maintain efficiency.

I look at the route choices. I've the choice between going straight or using the path]. I noticed these route choices on the map before registering the last control. We don't save much time while going straight in the vegetation instead of using the path, especially with my shoes problem. We lost some efficiency, and speed decreases too, because we've to pay attention to the vegetation.

I hesitate between the two routes half a second. I decide to use the path, because there's better efficiency and navigation is less risky.

Here, I'm slowing down to be sure to use the path, instead of going straight away through the vegetation.

Here I try to see on the terrain the crossroads I've noticed on the map. I don't see it yet.

I'm now on this turn which is at $1 \mathrm{~cm}$ [0.4 inch] on the map 75 meters

[246 feet] on the terrain. The path is going that way.

I know where I'm going so I maintain my speed.

I turn my head to check if the crossroads is there.

I'm arriving at the crossing path.

I now run on a path. There isn't any technical difficulty. I focus on my running pace.

I know I must leave the path at the turn here on the map.

I use this quiet time to prepare for the control approach and the direction of the following control.

Here I take the map with my two hands because there is a very large amount of information contained on the map. I want to reduce shaking I am trying to work out if the control is at the top, in the depression or re-entrant.

\begin{tabular}{|c|c|}
\hline \multicolumn{2}{|c|}{ Categories of concerns } \\
\hline First order & Second order \\
\hline $\begin{array}{l}\text { Simplify the map to } \\
\text { navigate }\end{array}$ & $\begin{array}{l}\text { Find the control faster } \\
\text { than the opponents }\end{array}$ \\
\hline $\begin{array}{l}\text { Simplify the map to } \\
\text { navigate }\end{array}$ & $\begin{array}{l}\text { Find the control faster } \\
\text { than the opponents }\end{array}$ \\
\hline Judging navigation & $\begin{array}{l}\text { Reflect on actions } \\
\text { undertaken during } \\
\text { performance } \\
\text { Optimize running } \\
\text { pace thorough the } \\
\text { race } \\
\text { Optimize running } \\
\text { pace thorough the } \\
\text { race }\end{array}$ \\
\hline $\begin{array}{l}\text { Use the shortest and } \\
\text { most energy-efficient } \\
\text { running routes }\end{array}$ & $\begin{array}{l}\text { Find the control faster } \\
\text { than the opponents }\end{array}$ \\
\hline $\begin{array}{l}\text { Use the shortest and } \\
\text { most energy-efficient }\end{array}$ & $\begin{array}{l}\text { Find the control faster } \\
\text { than the opponents }\end{array}$ \\
\hline
\end{tabular}

Use the shortest and most energy-efficient running routes

Simplify the map to navigate Simplify the map to navigate

Simplify the map to navigate Simplify the map to navigate

Simplify the map to navigate Simplify the map to navigate Simplify the map to navigate Simplify the map to navigate
Find the control faster than the opponents

Optimize running pace thorough the race

Find the control faster than the opponents Find the control faster than the opponents Optimize running pace thorough the race

Find the control faster than the opponents Find the control faster than the opponents Optimize running pace thorough the race

Find the control faster than the opponents Find the control faster than the opponents Find the control faster than the opponents Find the control faster than the opponents 
Table 2

Frequency of Concerns and their Ratios by Competition and Category of Concern

\begin{tabular}{|c|c|c|c|c|c|c|c|c|}
\hline \multirow[t]{2}{*}{ Competition } & \multirow{2}{*}{$\begin{array}{c}\text { Frequency } \\
\text { of } \\
\text { concerns }\end{array}$} & \multicolumn{3}{|c|}{$\begin{array}{l}\text { Find the controls faster than the } \\
\text { opponents }^{\dagger+}\end{array}$} & \multirow{2}{*}{$\begin{array}{l}\text { Optimize } \\
\text { running pace } \\
\text { throughout } \\
\text { the race }^{t+}\end{array}$} & \multicolumn{3}{|c|}{$\begin{array}{l}\text { Reflect on actions undertaken during } \\
\text { performance }^{\dagger+}\end{array}$} \\
\hline & & $\begin{array}{l}\text { Simplify } \\
\text { the map to } \\
\text { navigate }^{\dagger}\end{array}$ & $\begin{array}{l}\text { Use the } \\
\text { shortest and } \\
\text { most } \\
\text { energy- } \\
\text { efficient } \\
\text { running } \\
\text { routes }^{\dagger}\end{array}$ & Total & & $\begin{array}{c}\text { Judging } \\
\text { navigation }^{\dagger}\end{array}$ & $\begin{array}{c}\text { Deciding } \\
\text { whether to use } \\
\text { information } \\
\text { about } \\
\text { opponents }{ }^{\dagger}\end{array}$ & Total \\
\hline 1 & 207 & .49 & .19 & .68 & .15 & .13 & .04 & .17 \\
\hline 2 & 552 & .54 & .13 & .67 & .14 & .16 & .03 & .19 \\
\hline Total & 759 & .53 & .15 & .67 & .14 & .15 & .03 & .18 \\
\hline
\end{tabular}

Note: ${ }^{\dagger}$ First order concern ${ }^{\dagger \dagger}$ Second order concern 